\title{
Glycemic Variability, Glycated Hemoglobin, and Cardiovascular Complications: Still a Dilemma in Clinical Practice
}

\author{
Antonio Ceriello · Ali A. Rizvi · Manfredi Rizzo
}

Received: September 28, 2021 / Accepted: September 30, 2021 / Published online: November 10, 2021

(C) The Author(s), under exclusive licence to Springer Healthcare Ltd., part of Springer Nature 2021

\section{Key Summary Points}

HbA1c remains a very important laboratory measurement for patients with diabetes, although its sole use cannot be recommended for a comprehensive evaluation of their glycemic control.
A. Ceriello

IRCCS MultiMedica, Milan, Italy

A. A. Rizvi

Division of Endocrinology, Metabolism, and Lipids, Department of Medicine, Emory University, Atlanta, GA, USA

\section{A. A. Rizvi · M. Rizzo}

Division of Endocrinology, Diabetes and

Metabolism, University of South Carolina School of

Medicine Columbia, Columbia, SC, USA

\section{Rizzo}

Department of Health Promotion, Mother and Child Care, Internal Medicine and Medical Specialties (Promise), University of Palermo, Palermo, Italy

A. A. Rizvi $(\bowtie)$

Division of Endocrinology, Metabolism, and Lipids, Department of Medicine, Emory University, Emory Johns Creek Hospital, Hospital Pkwy, Johns Creek, GA 30097, USA

e-mail: Ali.Rizvi@ucf.edu
Proper management of glycemic variability contributes to improve the cardiometabolic outcome in patients with type 2 diabetes mellitus regardless of HbA1c levels.

We highly recommend the evaluation of glycemic variability in clinical practice, together with the usual measurements of HbA1c and fasting glucose.

\section{EDITORIAL}

In the present issue of Advances in Therapy, Li et al. [1] have investigated the relationship between achieving glycemic targets and glycemic variability in Chinese patients with type 2 diabetes mellitus (T2DM). Despite some limitations due to the nature of their post hoc analysis, the authors did not find a significant association in reaching HbA1c target and glycemic variability. This finding seems to support the hypothesis that proper management of glycemic variability may contribute to improve the cardiometabolic outcome in patients with T2DM regardless of HbA1c [2]. Although the measurement of HbA1c is suggested by international scientific guidelines as a useful marker to evaluate glycemic control and with prognostic value for diabetes complications [3], 
some authors have discussed the inadequacy of the use of HbA1c as the sole marker, since its measurement in isolation can be even misleading [4].

Currently, HbA1c levels are well managed in patients with diabetes on medications with low hypoglycemia risk, which is something quite common in our days with the wide use of dipeptidyl peptidase 4 (DPP4) inhibitors, glucagon-like peptide 1 receptor agonists (GLP-1RAs), and sodium-glucose co-transporter 2 inhibitors (SGLT2i), as well as the new types of basal insulin analogues [3]. Yet, a large body of evidence suggests that glycemic variability should be also taken into account, beyond HbA1c [4]. Indeed, glycemic variability can not only be a dangerous condition for the cardiovascular system [2] but it is also associated with increased risk of hypoglycemia, which is strictly linked to adverse cardiovascular outcome and all-cause mortality [2]. Therefore, no further delay is allowed for the management and treatment of glucose variability, in order to ensure effective prevention of diabetic complications [5].

The mechanisms involved in the genesis and severity of adverse clinical outcomes due to glycemic variability have been investigated over the years and, overall, a direct role of glycemic variability in tissue damage has been highlighted, with oxidative stress as the key player in producing damage to endothelial cells [6]. Some authors have shown the relationship between daily and day-to-day glycemic variability and increased oxidative stress in patients with T2DM [7], as well as demonstrating that oscillating glucose is more deleterious to endothelial function and oxidative stress than mean glucose in patients with T2DM [8]. These preliminary observations were then completed with the finding of a strong association between glycemic variability and markers of vascular damage, including oxidative low-density lipoproteins (LDL) [9].

Indeed, diabetic dyslipidemia is usually formed by alterations in the quality rather than the quantity of LDL [10], with increased levels of denser LDL particles with smaller size, and greater atherogenicity, due to reduced LDL receptor affinity, higher susceptibility to oxidation, and greater arterial entry and retention [11]. Small, dense LDL particles are prevalent in several categories of patients at high cardiovascular risk, including T2DM and gestational diabetes [12-15], and have been recognized as an independent risk factor for cardiovascular diseases [11], being a key factor for the development and progression of atherosclerosis and endothelial dysfunction, which both amplify the risk of cardiovascular events [16]. Some inflammatory cytokines, such as resistin, are closely associated with small, dense LDL and seem to play a role in diabetes and cardiovascular diseases [17].

Of interest, some novel antidiabetic medications have shown favorable effects on glycemic variability [18], with interesting data coming from the use GLP-1RAs $[19,20]$ and SGLT-2i [21]. This is of great clinical importance, since the use of these novel antidiabetic agents in patients with T2DM results in glycemic control, metabolic benefit as well as a positive cardiovascular outcome [22]; on this basis, GLP-1RAs and SGLT2i are recommended as first-line antidiabetic therapies by current guidelines issued by both diabetologists and cardiologists [23]. In addition, some GLP-1RAs improve oxidative stress, endothelial dysfunction, subclinical atherosclerosis, and atherogenic small dense LDL [24-27], all of which seems to be key mechanisms for the tissue damage induced by glycemic variability, as discussed above.

In conclusion, HbA1c remains a very important laboratory measurement for patients with diabetes, although its sole use cannot be recommended for a comprehensive evaluation of their glycemic control; indeed, increasing evidence suggests the need to monitor not only HbA1c and fasting glucose but also postprandial glucose and glycemic variability [4]. Since the assessment of glycemic variability significantly contributes to proper management and treatment of patients with diabetes and also to prevent future complications [5], we highly recommend the evaluation of glycemic variability in clinical practice together with the usual measurements of $\mathrm{HbA} 1 \mathrm{c}$ and fasting glucose. 


\section{ACKNOWLEDGEMENTS}

Funding. No funding or sponsorship was received for this study or publication of this article.

Authorship. All named authors meet the International Committee of Medical Journal Editors (ICMJE) criteria for authorship for this article, take responsibility for the integrity of the work as a whole, and have given their approval for this version to be published.

Authors' Contributions. All named authors have contributed equally to the present article, in its concept and design, drafting and revision.

Disclosures. Antonio Ceriello, Ali Abbas Rizvi, and Manfredi Rizzo declare that this article has been written independently, without any financial or professional help, and reflects only the opinion of the authors, without any role of the industry. Since the completion of the work, Ali Abbas Rizvi's new affiliation is the University of Central Florida College of Medicine, Orlando, FL, United States.

Compliance with Ethics Guidelines. This article is based on previously conducted studies and does not contain any new studies with human participants or animals performed by any of the authors.

\section{REFERENCES}

1. Li L, Yang $\mathrm{T}$, Xue $\mathrm{Y}$, et al. Influence of fasting plasma glucose targets on glycemic variability in Chinese participants with type 2 diabetes: a post hoc analysis of the FPG GOAL trial (BEYOND III). Adv Ther. https://doi.org/10.1007/s12325-02101932-2

2. Ceriello A, Monnier L, Owens D. Glycaemic variability in diabetes: clinical and therapeutic implications. Lancet Diabetes Endocrinol. 2019;7: 221-30.

3. American Diabetes Association. 6. Glycemic targets: standards of medical care in diabetes-2021. Diabetes Care. 2021;44:S73-84.
4. Beck RY, Connor CG, Mullen DM, Wesley DM, Bergenstal RM. The fallacy of average: how using HbA1c alone to assess glycemic control can be misleading. Diabetes Care. 2017;40:994-999.

5. Ceriello A. Glucose variability and diabetic complications: is it time to treat? Diabetes Care. 2020;43:1169-71.

6. Quagliaro L, Piconi L, Assaloni R, Martinelli L, Motz E, Ceriello A. Intermittent high glucose enhances apoptosis related to oxidative stress in human umbilical vein endothelial cells: the role of protein kinase $\mathrm{C}$ and $\mathrm{NAD}(\mathrm{P}) \mathrm{H}$-oxidase activation. Diabetes. 2003;52:2795-804.

7. Ohara M, Fukui T, Ouchi M, et al. Relationship between daily and day-to-day glycemic variability and increased oxidative stress in type 2 diabetes. Diabetes Res Clin Pract. 2016;122:62-70.

8. Ceriello A, Esposito K, Piconi L, et al. Oscillating glucose is more deleterious to endothelial function and oxidative stress than mean glucose in normal and type 2 diabetic patients. Diabetes. 2008;57: 1349-54.

9. Dasari PS, Gandomani BS, Teague AM, Pitale A, Otto M, Short KR. Glycemic variability is associated with markers of vascular stress in adolescents. J Pediatr. 2016;172:47-55.e2.

10. Krauss RM. Lipids and lipoproteins in patients with type 2 diabetes. Diabetes Care. 2004;27:1496-504.

11. Rizzo M, Berneis K. Who needs to care about small, dense low density lipoproteins? Int J Clin Pract. 2007;61:1949-56.

12. Rizzo M, Pernice V, Frasheri A, Berneis K. Atherogenic lipoprotein phenotype and LDL size and subclasses in patients with peripheral arterial disease. Atherosclerosis. 2008;197:237-41.

13. Rizzo M, Spinas GA, Cesur M, Ozbalkan Z, Rini GB, Berneis K. Atherogenic lipoprotein phenotype and LDL size and subclasses in drug-naïve patients with early rheumatoid arthritis. Atherosclerosis. 2009;207:502-6.

14. Goedecke JH, Utzschneider $\mathrm{K}$, Faulenbach MV, et al. Ethnic differences in serum lipoproteins and their determinants in South African women. Metabolism. 2010;59:1341-50.

15. Rizzo M, Berneis $\mathrm{K}$, Altinova AE, et al. Atherogenic lipoprotein phenotype and LDL size and subclasses in women with gestational diabetes. Diabet Med. 2008;25:1406-11.

16. Corrado E, Rizzo M, Coppola G, Muratori I, Carella M, Novo S. Endothelial dysfunction and carotid 
lesions are strong predictors of clinical events in patients with early stages of atherosclerosis: a 24-month follow-up study. Coron Artery Dis. 2008;19:139-44.

17. Abate N, Sallam HS, Rizzo M, et al. Resistin: an inflammatory cytokine. Role in cardiovascular diseases, diabetes and the metabolic syndrome. Curr Pharm Des. 2014;20:4961-9.

18. Kim NH, Kim DL, Kim KJ, et al. Effects of vildagliptin or pioglitazone on glycemic variability and oxidative stress in patients with type 2 diabetes inadequately controlled with metformin monotherapy: a 16-week, randomised, open label, pilot study. Endocrinol Metab (Seoul). 2017;32: 241-7.

19. Frías JP, Nakhle S, Ruggles JA, et al. Exenatide once weekly improved 24-hour glucose control and reduced glycaemic variability in metformin-treated participants with type 2 diabetes: a randomized, placebo-controlled trial. Diabetes Obes Metab. 2017;19:40-8.

20. Xing Y, Chen J, Zhao L, Ma H. Analysis of the effect of liraglutide on glycemic variability in patients with type 2 diabetes. Endocr J. 2020;67:455-68.

21. Ceriello A, Ofstad AP, Zwiener I, Kaspers S, George J, Nicolucci A. Empagliflozin reduced long-term HbA1c variability and cardiovascular death: insights from the EMPA-REG OUTCOME trial. Cardiovasc Diabetol. 2020;19:176.
22. Giorgino F, Caruso I, Moellmann J, Lehrke M. Differential indication for SGLT-2 inhibitors versus GLP-1 receptor agonists in patients with established atherosclerotic heart disease or at risk for congestive heart failure. Metabolism. 2020;104:154045.

23. Maranta F, Cianfanelli L, Rizzo M, Cianflone D. Filling the gap between guidelines and real world in the cardiovascular approach to the diabetic patients: the need for a call to action. Int J Cardiol. 2021;15(329):205-7.

24. Rizzo M, Rizvi AA, Patti AM, et al. Liraglutide improves metabolic parameters and carotid intimamedia thickness in diabetic patients with the metabolic syndrome: an 18-month prospective study. Cardiovasc Diabetol. 2016;15:162.

25. Anholm C, Kumarathurai P, Pedersen LR, et al. Liraglutide in combination with metformin may improve the atherogenic lipid profile and decrease C-reactive protein level in statin treated obese patients with coronary artery disease and newly diagnosed type 2 diabetes: a randomized trial. Atherosclerosis. 2019;288:60-6.

26. Nikolic D, Giglio RV, Rizvi AA, et al. Liraglutide reduces carotid intima-media thickness by reducing small dense low-density lipoproteins in a real-world setting of patients with type 2 diabetes: a novel anti-atherogenic effect. Diabetes Ther. 2021;12: 261-74.

27. Nauck MA, Quast DR, Wefers J, Meier JJ. GLP-1 receptor agonists in the treatment of type 2 diabetes - state-of-the-art. Mol Metab. 2021;46:101102. 